\title{
An Unexpected Affordance of Program Design for Dissertation Writing During COVID-19: The Embedded Dissertation
}

\author{
Sarah Capello \\ Judson University \\ sarah.capello@judsonu.edu \\ Mellissa Gyimah-Concepcion
Judson University \\ mellissa.gyimah-concepcion@judsonu.edu \\ Victoria Vandover Billimack \\ Judson University \\ victoria.billimack@judsonu.edu
}

\begin{abstract}
Purpose: This paper describes how an embedded dissertation program design feature supported two cohorts of EdD dissertators and helped them make consistent progress toward and eventually complete their dissertation milestones during the COVID-19 pandemic. Specifically, we detail the work, challenges, and results of EdD students' efforts toward their milestones and offer perspectives on the same topics for EdD faculty who are teaching dissertation writing courses or supporting dissertators during the COVID-19 pandemic.

Conceptual Argument: This paper argues that an existing program design feature, the embedded dissertation, provided unexpected affordances for EdD dissertators during the COVID-19 pandemic. Specifically, it acted as a scaffold for dissertators to make small but consistent steps forward on their dissertation milestones despite the significant challenges they faced both as practitioners and as students during the pandemic.

Implications for Research: In sharing these experiences, we hope to: (a) offer a contribution to the literature on the intersection of program design and dissertation writing, (b) proffer a program design structure that was successful in moving dissertators forward during COVID-19, and (c) document the lived experiences of EdD dissertators and faculty in this unprecedented, historical moment.
\end{abstract}

\section{KEYWORDS}

education doctorate, dissertation writing, program design, COVID-19

\section{INTRODUCTION}

EdD degree completion rates are notoriously low. While recent research estimates a $40-60 \%$ attrition rate for students in traditional doctoral programs (Cassuto, 2013; Council of Graduate Schools, 2012; Rockinson-Szapkiw et al., 2019), some studies have found attrition rates of up to $70 \%$ for EdD students (Bowen \& Rudenstine, 1992; Nettles \& Millett, 2006), and there is evidence that online doctoral programs have even higher attrition rates (Bawa, 2016). These rates are startling not only because they are so high, but because there has been an increase in the number of both

New articles in this journal are licensed under a Creative Commons Attribution 4.0 United States License. residential and online EdD programs in the past decade. Program administrators must ensure that, if they are going to enroll EdD students, they are providing pathways and support for students to complete their degrees. Encouragingly, EdD programs have begun to receive renewed attention stemming from critiques that they provided irrelevant, non-rigorous curriculum, were not differentiated from $\mathrm{PhD}$ programs, and resulted in low-quality dissertations and large numbers of "all but dissertation" (ABD) students (Levine, 2005; Perry, 2015; Schulman et al., 2006). In response to these critiques, the Carnegie Project on the Education Doctorate (CPED) has led the 
charge to reform EdD programs and proposed a framework to transform EdD education (CPED, 2019; Perry, 2015).

Although programmatic variables and student characteristics have both been shown to contribute to EdD students' degree persistence (Rockinson-Szapkiw et al., 2019; Tinto, 1993), this article focuses on the intersection between program design and dissertation writing, which is an academic competency critical for doctoral student success. Despite the dissertation being placed at the end of doctoral programs, many doctoral students need writing support at the dissertation stage (Rose \& McClafferty, 2001; Salee et al., 2011), which indicates that program coursework and activities are not preparing students well enough for dissertation writing. Some programs have attempted to provide additional writing support by teaching academic writing in coursework (Rose \& McClafferty, 2001; Salee et al., 2011), utilizing peer-review at the dissertation stage (Capello, 2020; Crossman \& Kite 2012), and implementing dissertation writing groups (Aitchison, 2009; Ferguson, 2009; Maher et al., 2008). However, if EdD completion rates are an indicator of the effectiveness of these writing interventions, then it appears thateven in the best of times-existing efforts to support dissertation writing alone are insufficient to overcome barriers to degree completion.

Unfortunately, we are existing in difficult times. Beginning in March 2020, American post-secondary institutions closed their physical doors and moved many courses to a remote learning format due to the COVID-19 pandemic. Many states also closed K-12 schools and moved to remote learning, shut down non-essential businesses, and quarantined residents at home. At the time of this writing, there is much uncertainty as to whether and when postsecondary institutions and K-12 schools will resume in-person classes. Despite these challenges, it is crucial for EdD-granting institutions to continue to provide and even bolster support for EdD dissertators (those working on their dissertations) who are at the final, and perhaps most difficult, phase of their programs. In this article, we highlight one strategy an EdD program in the Midwest is using to provide ongoing support to EdD dissertators during the COVID-19 pandemic: the embedded dissertation. This program design feature supports dissertators via coursework throughout the dissertation phase of the program. We argue that, despite significant challenges stemming from the COVID-19 pandemic, the embedded dissertation design afforded EdD students and faculty a structural and social support that bolstered student success in maintaining adequate progress and eventually completing dissertation milestones during the pandemic.

In this paper, we first describe the embedded dissertation program design at Prairieview College (a pseudonym) and how the COVID-19 pandemic affected the institution, EdD dissertators, and EdD faculty. Then, we report the work of three EdD faculty who taught dissertation writing courses remotely, the challenges students and faculty faced, and the results of our efforts. We conclude by communicating the significance of this inquiry for EdD program administrators and faculty who are interested in restructuring their programs to support dissertation writing. In this article, we remain focused only on EdD dissertators and the faculty who were working with them during the spring and summer 2020 semesters as a study of how program design can support dissertation writing during and after a national pandemic.

\section{THE EMBEDDED DISSERTATION AT PRAIRIEVIEW COLLEGE}

The EdD program at Prairieview College is a 4-year program with a concentration in literacy that primarily attracts K-12 teachers, administrators, literacy specialists, and librarians. The embedded dissertation program design is an attractive and important feature for many of our students. Unlike traditional EdD programs where students complete coursework and then embark upon their dissertations, students at Prairieview complete their dissertation work (e.g., proposal writing, data collection and analysis, dissertation chapter writing and revising) as part of their coursework. Broadly speaking, our students write a dissertation proposal in the spring of their second year, defend, revise, and obtain IRB approval over the summer, collect data in the fall of the third year, analyze data that spring, then write and revise their full dissertations through the summer. Students submit the dissertation to their committees and defend during the fourth year. Figure 1 displays the embedded dissertation course structure.

Figure 1. Embedded Dissertation Course Structure

\begin{tabular}{|l|l|l|l|l|l|l|}
\hline \multicolumn{2}{|c|}{ Year 2 } & \multicolumn{2}{c|}{ Year 3 } & \multicolumn{2}{l|}{ Year 4 } \\
\hline Fall & Spring & Summer & Fall & Spring & Summer & Fall \\
\hline & $\begin{array}{l}\text { EDU 100 - Write Dissertation } \\
\text { Proposal }\end{array}$ & $\begin{array}{l}\text { EDU 120- Data } \\
\text { Collection }\end{array}$ & $\begin{array}{l}\text { EDU 130 \& 140 - } \\
\text { Data Analysis }\end{array}$ & $\begin{array}{l}\text { EDU 150 -Draft final } \\
\text { dissertation chapters } \\
\text { EDU 200 - Revise and } \\
\text { edit dissertation }\end{array}$ & \\
& & & & Defend Dissertation \\
& Obtain IRB approval & & & \\
\end{tabular}

Note: All course names are pseudonyms.

As Figure 1 demonstrates, the embedded dissertation course sequence is comprised of six courses: three writing courses, one data collection course, and two data analysis courses. Collectively, we taught the three writing courses during the 2019-2020 academic year. Mellissa and Sarah taught EDU 100, a spring and summer course that met once a month where students finalize their research questions and study designs, write a dissertation proposal, defend their proposals, make any revisions stemming from the proposal defense, and submit institutional review board (IRB) applications.
We refer to the students who were taking EDU 100 at the time of the pandemic as Cohort A. We held two in-person meetings with this cohort in February and March 2020 before Prairieview moved to remote learning. At the end of the spring semester when we were in full-remote mode, Sarah had Cohort B, which was a year ahead of Cohort A, for EDU 150. In this weekly course, Cohort B was writing their findings and conclusion chapters stemming from their data analysis, which they completed in earlier courses (EDU 130 \& 140). After students complete EDU 150, they have a full dissertation draft comprised of five chapters: introduction, literature review, methods, findings, and conclusion. At this point, they progress to EDU 200, a 
dissertation writing workshop, where students continue to revise and edit their manuscripts. In the summer 2020, Vicki and two colleagues taught this course, which met multiple times per week from the beginning of June to mid-July.

The embedded dissertation program design has several benefits. First, it supports dissertators at every stage of the dissertation process and provides them consistent access to faculty and cohort members. Specifically, it allows for an intellectual space for students to pose questions and work through challenges with instructors and colleagues as well as functioning as a social space for students to share progress and encourage one another. Second, it allows faculty to check in with dissertators on a weekly basis and either assures them that students are making adequate progress or allows them to intervene if students are not. In doing so, this structure engenders constant communication between students and faculty during the dissertation writing process, which can be a lonely and frustrating endeavor.

As with any program design, the embedded dissertation does have several limitations that should be noted. First, the embedded dissertation timeline limits the type and breadth of study students can conduct. Studies with long data collection periods or research that seeks to demonstrate change over time are not a good fit for our program. Secondly, students move from one phase of the dissertation process to the next through coursework whether they are ready to progress or not. For example, if a student falls behind when writing her dissertation proposal, she may not be able to begin data collection until late fall. This, by default, puts her out of alignment with the data collection, data analysis, and writing courses that are scheduled to support those endeavors at specific times throughout the year. However, clear communication and guidance on research design from faculty and careful planning and action on the part of the dissertator can alleviate most of these tensions. Lastly, course offerings are limited because the courses sequence is designed to move the student through the dissertation process at a steady pace; therefore, there are no electives available for students to explore during the second or third years. This often has ramifications on students' broader understanding and knowledge of education research and research design outside the purview of their own studies. However, they do become experts in their specific topics and knowledgeable in literacy research, because their work is so streamlined.

\section{DISSERTATION WRITING AND TEACHING DURING COVID-19}

In addition to describing the embedded dissertation, in this paper we also explore how the embedded dissertation design resulted in unanticipated affordances for EdD students at the dissertation writing stage (rather than the data collection or data analysis stages) and for the faculty teaching the dissertation writing courses during the COVID-19 pandemic, primarily because this is the stage students and faculty were in when the pandemic struck. In this section, we discuss the work, the challenges, and the results of dissertation writing and instructing courses on dissertation writing during COVID-19 for both EdD faculty and students.

\section{The Work of Teaching Dissertation Writing Courses Remotely}

In March 2020, Prairieview College closed its physical campuses and moved to remote learning for an indeterminate period. At the time, one cohort of dissertators (Cohort $A$ ) were taking a dissertation proposal writing class, and another cohort (Cohort B) had nearly finished data analysis and were moving toward writing their findings and conclusion chapters. To keep our cohorts moving forward in their respective program timelines, we restructured our class meetings in the following ways. First, we used synchronous teleconferencing software for class and began each session with a 15 minute "check-in" time, which allowed students a social space to share what was happening in their personal and professional lives, thus offering socioemotional support. Since our state had quarantined residents at home, these check-in periods offered much needed social interaction for us and our students. Second, we scheduled active class time during which we introduced new content through mini lessons, class discussions, readings, short videos, and breakout sessions. Thirdly, we allotted significant amounts of class time (2-4 hours, depending on the course) for independent writing and periodic peer review. While students wrote independently, the instructors teleconferenced with each student individually and remained available remotely during the class meeting time to answer any questions that arose during the independent writing time. Since the outcomes of the writing courses were to complete a dissertation proposal (Cohort A) and write findings and concluding chapters while revising and editing the full dissertation (Cohort $\mathrm{B}$ ), we believed these revised activities and class structures would allow us to meet the stated goals in a remote format. Finally, we made ourselves available for teleconferencing outside of class hours, which provided the students with ongoing support and ensured that they were still on track and moving toward their individual and course goals. This was especially important for EDU 100, which only met once a month. At the end of that course, Mellissa and Sarah again met with each student individually via teleconferencing software so that we could discuss their dissertation proposal defenses, any revisions stemming from the defenses, and provide them guidance for their next endeavor: the IRB application. Vicki and colleagues also met with students individually at the end of EDU 200 to discuss elements of their dissertation drafts that needed additional attention before students submitted the drafts to their committees for review. We found it was just as critical to hold these end-of-the-course meetings with students so that we could clarify next steps and ensure no one fell through the cracks. Based on student feedback and our own reflections as instructors after the courses ended, we have determined that the objectives were, indeed, met even though we made drastic changes to our course structures.

\section{The Challenges of Dissertation Writing and Teaching during COVID-19}

As with many EdD students, our dissertators were primarily K12 practitioners. Within days of Prairieview announcing its move to remote learning, the majority of school districts that employ our students also moved to remote learning. The swiftness of these school closures and the uncertainty of their duration struck our students dramatically. Many experienced an extreme amount of stress as pressure built from administrators and parents in their districts to move their classrooms to remote learning platforms quickly. Furthermore, many of our students were locked out of their 
schools, could not retrieve books or other materials, and did not have access to office equipment such as printers and scanners at home. Similarly, Prairieview locked down campus, and dissertators could not access on-campus resources and technology. Finally, the library building at Prairieview closed, and the state interlibrary loan system partially shut down. Dissertators could access digital resources through the library system, but the number of available resources was drastically reduced. The combined result of these realities was that our students were hindered in their dissertation writing progress by an increase in time necessary to fulfill professional responsibilities combined with a lack of access to resources. As the weeks dragged on, our students became noticeably worn down from the demands of their new work, additional responsibilities of homeschooling their own children whose schools had closed, caring for elderly or at-risk family members, and trying to maintain progress on their dissertations.

Like our students, we were also locked out of our campus buildings, offices, and libraries and could not access our books, materials, office equipment, and supplies necessary for our courses. Furthermore, with the swift and sudden move to remote learning, we had to quickly adjust our ongoing courses to a remote format. Most of us had little remote teaching experience, were unsure of best instructional practices for remote learning, and did not have time to research them. Furthermore, Vicki and her co-instructors were adjunct faculty who also worked full-time in $\mathrm{K}-12$ schools and were facing many of the same challenges as their students who were employed in K-12 schools. Finally, our check-in times and individual conferences with students often led to students sharing the mental and emotional stress that they had been under. While we appreciated students' honesty and were thankful they felt comfortable sharing personal experiences and feelings during our check-ins, expressions of student stress made some of us feel as if we had been placed in a role of emotional management (Hochschild, 1983/2012). Not only were we trying to manage our own stress and emotions during the pandemic, but we became tasked with supporting our students' socioemotional needs as well. While we embraced the notion that our students felt comfortable with us enough to view us as their support, we quickly realized that we, too, were worn down with the demands of our personal lives, our professional lives, and now the additional, evolving role of teachercounselor-all during a pandemic.

\section{Dissertator Success during COVID-19}

Even with the considerable challenges involved with writing and teaching remotely during the COVID-19 pandemic, our students' completed milestones, and our reflections on our students' progress during this time suggest positive results for EdD dissertators due to the embedded dissertation program design. First, all students in Cohort A completed dissertation proposals, defended them, and are, at the time of this writing, on track with their typical fall dissertation activities. Similarly, all students in Cohort B successfully completed their full dissertation drafts and are currently preparing for their defenses. Thus, the dissertators all succeeded in completing the two major goals we had for them at that stage and are currently where they would have been in a more typical year. Because of this, we conclude that our dissertators made the same, if not more, progress on their milestones than prior cohorts despite significant personal and professional challenges due to COVID-19. We believe this was due to a combination of benefits afforded by remote learning and the embedded dissertation design. For example, because they were not on campus for class, our students were able to write in a setting where they felt comfortable and when they were ready, rather than being forced to write during class time on campus. In prior years, it was common for students to express that they found it difficult to write on campus, and they had regularly asked to leave class early so they could write at home. Not having to commute to work or campus also allowed dissertators more time to write. Furthermore, Vicki found that one-on-one remote conferences with students were more productive and that students asked more focused questions than in previous years. This may have occurred because faculty were able to provide feedback quicker since we were also not commuting to work or campus. Thirdly, our synchronous, weekly check-in meetings, peer review sessions, and instructor-student conferencing allowed students a social space to share frustrations and concerns but also to encourage one another. Then, moving into asynchronous, independent work time gave students large chunks of time to work on their dissertation proposals and manuscripts. Students received more time than they typically would in class to peer review and confer with us, and they seemed to find this incredibly beneficial. Most importantly, moving our courses to a remote format allowed for the health and safety of the students, faculty, and staff at Prairieview as well as their family, colleagues, and community members.

Faculty also benefitted from the move to remote instruction since it allowed us to be available to students remotely during independent work time but also allowed us to read and comment on chapters in a comfortable setting when students did not need us. Furthermore, a characteristic of the embedded dissertation is a shared workload among faculty, so distributing the work of reading and commenting on many chapters of student writing among multiple instructors helped reduce the workload and avoid faculty burnout, which can be high in normal times (Padilla \& Thompson, 2016), but may have been even more so for doctoral faculty supporting dissertators during the pandemic. Finally, the unforeseen reality of forced remote learning opened our eyes to new possibilities for dissertation writing courses. Due to our students' success on their milestones this year and the benefits to students and faculty described previously, we are considering moving our writing courses to a remote or hybrid format permanently. The pandemic has essentially made us more willing to take risks and become more innovative with our instruction. After reflecting on our experiences during forced remote learning,- -and since we are still in the midst of the pandemic - we have decided to make a current research methods class hybrid. We are also currently finding ways to engage students when they are not in class, while teaching them valuable information and helping them to apply it to real world situations. For example, in a separate research course Mellissa and Sarah teach, we have our students doing a virtual tour of the Jane Addams Hull House. We asked them to place themselves in any era pre-Civil Rights, choose a women's rights issue they wanted to take up as their research interest and then design a study that they believe would work toward emancipating women. One student wrote in response to the assignment: "It was nice to apply the research learning outside of education topics to see if I really understood it" (Personal communication, Sept, 2020). We do not think we would have chosen to branch out in this way, had we not had success with remote learning in the previous semester.

While some of the positive student outcomes could be attributed to remote learning in general, it is important to note that the embedded dissertation design was the structure upholding dissertator progress in the remote setting. The remote format 
afforded benefits such as time to write in a comfortable setting, but we believe that the coursework and activities required within the embedded dissertation (e.g., turning in assignments, conferring with instructors, revising chapters) were the levers for success.

Furthermore, the embedded dissertation created a current that swept our students along and kept them moving forward even if they needed an extension on a chapter or if a draft needed more polishing than it might have in a typical year. As a result, the small successes of progressing forward gave dissertators hope and a sense of accomplishment during the stressful early months of the pandemic. These results demonstrate that, while remote learning due to COVID-19 presented significant challenges for EdD dissertators, the embedded dissertation program design was a successful scaffold in helping them overcome those challenges and did so by providing stability and goals along the way.

\section{SIGNIFICANCE FOR PRACTICE}

At the time of this writing, EdD faculty and students are currently processing the trauma, setbacks, and disappointments caused by the COVID-19 pandemic, and the field is in the preliminary stages of leaning about and from the effects of the pandemic on EdD students and programs. There is much to be documented, discussed, and learned as we move forward educating EdD students in remote and hybrid learning formats. In this paper, we relate how an existing program design helped EdD dissertators maintain progress and complete their dissertation milestones and actually resulted in unexpected benefits for EdD faculty and students during the pandemic. If our students can complete these milestones to the same degree as prior students during the incredible stress and uncertainty caused by the pandemic, there is much room for hope that the embedded dissertation design can support EdD dissertators in more "normal" years. Notably, our EdD program, which has employed the embedded dissertation design since the onset of the program six years ago, boasts a degree completion rate of over $90 \%$. These outcomes have significant implications for the connection between EdD program design and student retention, persistence, and graduation rates. While we realize that programs may not be able to make major, structural changes to their program designs easily or quickly, EdD program administrators may want to consider how embedding elements of dissertation writing into coursework and how synchronous social interactions in remote learning could support student persistence and completion at the dissertation stage, especially during the COVID-19 or other health pandemics. For years, scholars have been calling for a well-defined and distinct EdD degree (Levine, 2005; Schulman et al., 2006) that is a professional practice doctorate designed to prepare twenty-first century educational leaders rather than a PhD-lite degree (Perry, 2015; Schulman et al., 2006). The COVID-19 pandemic may be the disrupting force institutions need to reexamine how their EdD program designs are affecting doctoral student persistence and to reimagine innovative program design in these uncertain times. For those interested, the Carnegie Project on the Education Doctorate (2019) offers a framework for (re)designing and transforming EdD programs to meet the demand for preparing twenty-first century educational leaders.

\section{REFERENCES}

Aitchison, C. (2009). Writing groups for doctoral education. Studies in Higher Education, 34(8), 905-916. https://doi.org/10.1080/03075070902785580

Capello, S. A. (2020). Leveraging PhD students to support EdD dissertation writing. Impacting Education: Journal on Transforming Professional Practice, 5(3), 8-13. https://doi.org/10.5195/ie.2020.110

Bawa, P. (2016). Retention in online courses: Exploring issues and solutions-A literature review. SageOpen, 6(1), 1-11. https://doi.org/10.1177/2158244015621777

Bowen, W., \& Rudenstine, N. (1992). In pursuit of the Ph.D. Princeton University Press.

Carnegie Project on the Education Doctorate. (2019). The CPED framework. Retrieved from https://www.cpedinitiative.org/the-framework

Cassuto, L. (2013). Ph.D. attrition: How much is too much? The Chronicle of Higher Education. Retrieved from http://chronicle.com/article/PhDAttrition-How-Much-Is/140045

Crossman, J. M., \& Kite, S. L. (2012). Facilitated improved writing among students through directed peer review. Active Learning in Higher Education, 13(3), 219-229. https://doi.org/10.1177/1469787412452980

Council of Graduate Schools. (2012). Attrition and completion. Retrieved from http://cgsnet.org/attrition-and-completion

Ferguson, T. (2009). The 'write' skills and more: A thesis writing group for doctoral students. Journal of Geography in Higher Education, 33(2), 285 297. https://doi.org/10.1080/03098260902734968

Hochschild, A. (1983/2012). The managed heart: Commercialization of human feeling $\left(2^{\text {nd }}\right.$ ed.). University of California Press.

Levine, A. (2005). Educating school leaders. The Woodrow Wilson National Fellowship Foundation.

Maher, D., Seaton, L., McMullen, C., Fitzgerald, T., Otsuji, E., \& Lee, A. (2008). "Becoming and being writers": The experiences of doctoral students in writing groups. Studies in Continuing Education, 30(3), 263275. https://doi.org/10.1080/01580370802439870

Nettles, M. T., \& Millett, C. M. (2006). Three magic letters: Getting to Ph.D. Johns Hopkins University Press.

Padilla, M. A., \& Thompson, J. N. (2016). Burning out faculty at doctoral research universities. Stress and Health, 32, 551-558. https://doi.org/10.1002/smi.2661

Perry, J. A. (2015). The Carnegie project on the education doctorate. Change, The Magazine of Higher Learning, 47(3), 56-61. https://doi.org/10.1080/00091383.2015.1040712

Rockinson-Szapkiw, A., Holmes, J., \& Stephens, J. S. (2019). Identifying significant personal and program factors that predict online EdD students' program integration. Online Learning Journal, 23(4), 313-335. http://dx.doi.org/10.24059/olj.v23i4.1579

Rose, M., \& McClafferty, K. A. (2001). A call for the teaching of writing in graduate education. Educational Researcher, 30(2), 27-33. https://doi.org/10.3102/0013189X030002027

Salee, M., Hallett, R., \& Tierney, W. (2011). Teaching writing in graduate school. College Teaching, 59, 66-72. https://doi.org/10.1080/87567555.2010.511315

Schulman, L. S., Golde, C. M., Bueschel, A. C., Garabedian, K. J. (2006). Reclaiming education's doctorates: A critique and a proposal. Educational Researcher, 35(3), 25-32. https://doi.org/10.3102/0013189X035003025

Tinto, V. (1993). Leaving college: Rethinking the causes and cures of candidate attrition (2nd ed.). The University of Chicago Press. 